\title{
REFLEXIONES EN TORNO AL ENCAJE INSTITUCIONAL DE LA ORGANIZACIÓN DIRECTIVA EN LOS MUNICIPIOS DE RÉGIMEN COMÚN
}

\author{
Marifé Blanes Soliva \\ Departamento Derecho Constitucional, Ciencia Política y de la Administración \\ Universitat de València \\ Contacto: maria.f.blanes@uv.es
}

Fecha de recepción: 01/01/2017

Fecha de aceptación: 03/04/2017

\begin{abstract}
Resumen
El objeto de reflexión de este artículo parte del estudio de la legislación básica de régimen local, así como la doctrina y la jurisprudencia constitucional, con el fin de analizar el encaje institucional de la dirección pública en la organización de la gran mayoría de los municipios españoles: los municipios de régimen común. Dos elementos centran este artículo, de un lado, la dirección pública; y, de otro, la Administración local. Nos proponemos analizar la creación de estructuras directivas también en los municipios de régimen común a través de la legislación autonómica y la reglamentación local.
\end{abstract}

Palabras clave: Administración local, dirección pública, gestión pública, liderazgo, distribución competencias constitucionales

REFLECTIONS AROUND THE INSTITUTIONAL STRUCTURE OF THE PUBLIC MANAGMENT IN THE MUNICIPALITIES OF COMMON REGIME

\section{Summary}

The object of reflection of this article is based on the study of the basic legislation of local regime, as well as the doctrine and the constitutional jurisprudence. With the purpose of analyzing the institutional fit of the public management in the organization of the great majority of the Spanish municipalities: The municipalities of common regime. Two elements focus this article, on the one hand, the public address; And, on the other hand, the local administration. We propose to analyze the creation of management structures also in the municipalities of common regime through the regional legislation and local regulation.

Key words: Local administration, public management, leadership, distribution constitutional competencies 


\section{INTRODUCCIÓN.}

El tratamiento riguroso de la dirección pública en la historia de la Administración española es reciente. Antes de profundizar en la situación de la dirección publica en los municipios de régimen común, objeto de nuestro estudio, creemos necesario efectuar un somero análisis sobre la necesidad o no de contar con una dirección pública profesional en el seno de las entidades locales.

En los inicios de los aparatos burocráticos las funciones directivas en las administraciones se situaban en el ámbito de la política, el resto de funciones se entendían administrativas y se confiaban, en el seno de la entidad, al personal funcionario. Durante bastante tiempo en España ser directivo o directiva pública implicaba formar parte del Gobierno, el resto de personal público formaba parte de la organización administrativa encargándose exclusivamente de la aplicación de las normas administrativas y la ejecución de instrucciones (Villoría Mendieta, 2000, p. 282.).

La construcción decimonónica del modelo organizativo de las Administraciones públicas partía de dos premisas principales: los responsables políticos contaban con capacidad estratégica y eran los facultados para formular las metas y objetivos de los departamentos, esencia de la política; y al personal funcionario se le encomendaba la aplicación y la puesta en práctica los objetivos previamente diseñados políticamente.

Esta distribución de roles se mantuvo prácticamente inalterable hasta finales del siglo pasado. En el tránsito hacia el Siglo XXI países como Portugal, Gran Bretaña, Irlanda o Italia en mayor o menor medida, cuenten o no con una estructura directiva diferenciada del resto de la organización administrativa, han incidido en la reforma del espacio directivo en sus respectivas Administraciones, tanto en sus estructuras estatales como en el resto de Administraciones regionales o de segundo nivel, así como en sus entidades dependientes. Estas reformas han profundizado en la definición de las funciones directivas en el seno de la organización administrativa, así como en la profesionalización y la capacidad de liderazgo de los titulares de los puestos directivos.

Existen distintas definiciones del espacio directivo en las Administraciones, a efectos de este estudio partimos del concepto utilizado por la OCDE, por el que el espacio directivo estaría conformado por el "sistema de personal estructurado y reconocido, relativo a puestos administrativos del más alto nivel pero de naturaleza no política" (OCDE, 2008). Por su parte, el Texto refundido de la Ley del Estatuto Básico del Empleado Público (TREBEP, en adelante) define al personal directivo como aquel que: "desarrolla funciones directivas profesionales en las Administraciones Públicas, definidas como tales en las normas específicas de cada Administración" ${ }^{1}$.

En otros términos, para nuestra legislación más reciente serán directivos públicos, el personal que en el seno de la estructura administrativa desempeña puestos o cargos calificados de directivos por la propia Administración. De hecho, en todas las Administraciones, incluidas las generales, existe un conjunto de puestos que se califican como directivos, empezando por la del Estado con la Ley 40/2015, de 1 de octubre, de

\footnotetext{
${ }^{1}$ Real Decreto Legislativo 5/2015, de 30 de octubre, por el que se aprueba el texto refundido de la Ley del Estatuto Básico del Empleado Público. Artículo 13. Personal directivo profesional.
} 
Régimen Jurídico del Sector Público $y$, por lo que nos interesa, para nuestras Administraciones locales a través de la Ley 7/1985, de 2 de abril, reguladora de las Bases del Régimen Local y sus modificaciones posteriores (LRBRL, en adelante).

Hay que hacer notar que una de las primeras dificultades al profundizar en el estudio de la dirección pública es su difícil delimitación en el seno de las Administraciones públicas en general, y en las Administraciones locales en particular. Es difícil ofrecer una definición de la dirección pública en el seno de las Administraciones locales porque ésta no es exclusivamente una definición jurídica. Siguiendo a Jiménez Asensio (1996: 275) podemos agrupar a los directivos públicos en torno a tres grandes grupos o círculos de funciones directivas, distinguiendo:

1. Un círculo de dirección política en dónde incluiríamos a ministros, presidentes de gobiernos regionales $\mathrm{y}$, en el ámbito local, alcaldes o electos locales. En este círculo directivo por regla general no se precisan de conocimientos técnicos o administrativos para desempeñar el cargo.

2. Un círculo de dirección político-administrativa. En el que se desarrollan tanto funciones con un componente político como funciones estrictamente administrativas o técnicas. En este círculo, situaríamos los denominados altos cargos del Estado y Comunidades Autónomas (los directores generales, subsecretarios, secretarios generales, y viceconsejeros). También habría que incluir al personal eventual de confianza política (asesores ejecutivos, miembros de los gabinetes ministeriales con relación eventual, y directores de gabinete o área en la administración local). Finalmente, también formarían parte este círculo, los altos cargos mercantiles de las sociedades públicas, que formen parte del consejo de administración; así como los directivos con contratos laborales de alta dirección en las Administraciones dependientes.

3. Un círculo de dirección burocrática, conformado por los niveles superiores del servicio civil de carrera. En este círculo, se localiza la élite burocrática, que está adscrita a las instituciones ejecutivas o administrativas del Estado en virtud de una relación profesionalizada; la cual, está sujeta a la disciplina y jerarquización propia de la estructura burocrática, aunque con indudable influencia en el proceso de decisión política. En este grupo, se incluyen los directivos cuya relación sea de naturaleza funcionarial (los subdirectores generales y puestos análogos en la Administración del Estado y autonómica, directores de servicios en la administración local, delegados y directores provinciales o regionales, etc).

Todas las personas que desempeñan su trabajo en estos espacios directivos, constituyen en su conjunto, el nivel directivo de nuestras Administraciones públicas. Ahora bien, a efectos de este estudio centraremos nuestro análisis en este segundo escalón directivo definido por el profesor Jiménez Asensio, el círculo político administrativo, el espacio dónde consideramos se hace necesario repensar sobre la oportunidad de su introducción en las estructuras organizativas de los municipios de régimen común. Por ello, no profundizaremos en las peculiaridades directivas de los otros dos espacios el personal político o el burocrático.

Tampoco podremos adentrarnos en este trabajo en otro problema no menor que afecta al estudio de la dirección pública en nuestras administraciones: la ausencia de un régimen jurídico homogéneo aplicable a todas las situaciones de naturaleza directiva 
existentes en nuestras Administraciones locales. Excluyendo a los electos locales, podemos encontrar en el espacio directivo situaciones jurídicas muy dispares, que hace que el directivo o directiva pública pueda estar sujeta a distintos regímenes jurídicos: régimen funcionarial o contratación laboral bajo la modalidad del contrato especial de alta dirección. Cuestiones éstas que merecerán otro trabajo.

Ante el laberinto normativo en el que nos encontramos en materia de dirección pública local, hemos creído necesario analizar la posibilidad de institucionalizar la dirección pública profesional también en los municipios de régimen común, como ocurre para las grandes ciudades.

\section{ANTECEDENTES DE LA DIRECCIÓN PÚBLICA EN LA LEGISLACIÓN LOCAL.}

La Administración local anterior a la Constitución de 1978 se caracterizó por la ausencia del carácter representativo de su nivel político y la debilidad de su estructura funcionarial. Antes del 78 únicamente los funcionarios de los Cuerpos Nacionales de Administración local, tenían presencia en todos los Ayuntamientos. Este cuerpo de funcionarios se crea con el Estatuto Municipal de 1924². El Estatuto les convierte en miembros de la Corporación con facultades como la advertencia de ilegalidad, además de exigir títulos y estudios para el ingreso por oposición en el cuerpo. Hay que hacer notar, que estos funcionarios desempeñaron funciones de control de la actividad municipal más que actividades de gestión o directivas propiamente dichas. Pese a todo, la legislación local fue la primera normativa española en reconocer la figura directiva o gerencial en el vértice de la organización municipal.

En los primeros años de la Transición, el Real Decreto 3046/1977, de 6 de octubre, por el que se articula parcialmente la Ley 41/1975, de Bases del Estatuto de Régimen Local, en lo relativo a los funcionarios públicos locales y otros extremos, diferencia como novedad, las funciones a desempeñar por los Concejales y, aquellas otras a desempeñar por los funcionarios, los cuales a su vez podían ser de carrera o empleo ${ }^{3}$. Los funcionarios de empleo local eran nombrados por el Pleno, salvo casos de urgencia, en que podían ser nombrados por la Comisión municipal permanente, en aquellos Ayuntamientos donde existiese, con la posterior ratificación del Pleno. Para el nombramiento de los funcionarios de empleo, se debía contar con la titulación adecuada para desempeñar el puesto, resultando nulos los nombramientos efectuados para asesoramiento especial a favor de personas carentes de la titulación adecuada. Asimismo eran nulos los nombramientos de empleo efectuados con carácter indefinido, o sin concretar su duración, así como la no inclusión en el contrato de su carácter administrativo. En todo caso, al producirse la renovación de la Corporación se producía el cese automático de este tipo de personal.

Por lo que interesa a nuestro estudio se preveía una modalidad específica de funcionarios de empleo de carácter directivo: los Directores de servicios. Nombrados y

\footnotetext{
${ }^{2}$ Real Decreto Ley de 8 de marzo de 1924 aprobando el Estatuto Municipal. Gaceta Madrid núm. 69 de 9 de marzo de 1924.

3 Norma derogada por el Real Decreto Legislativo 781/1986, de 18 de abril, aunque ya había sido parcialmente derogada en que se oponía a la Ley $7 / 1985$, de 2 de abril, reguladora de las Bases del Régimen Local.
} 
removidos libremente por el Pleno a propuesta de los Alcaldes, entre personas con la titulación, aptitud y experiencia adecuada para estar al frente de cada rama o servicio especializado cuando la complejidad de los servicios de competencia municipal lo aconsejara (art. 106, Ley 41/1975).

El cargo de Directores de servicio era incompatible con el de miembro de la entidad, sin embargo, les eran de aplicación las causas de incapacidad e incompatibilidad de Concejales. En relación a sus funciones, podía asistir con voz pero sin voto a las sesiones del Pleno o Comisión Permanente o de Gobierno para informar o asesorar de los asuntos que le solicite el Alcalde o la mayoría de los miembros de la Corporación.

Así pues, en los primeros años de la transición a la democracia cuando la complejidad de los servicios propios de la competencia municipal así lo aconsejaba, las funciones directivas eran desempeñadas por los Directores de servicio, es decir, la dirección pública se ejercía por funcionarios de empleo eventuales, nombrados y removidos libremente, es decir, bajo criterios de exclusiva confianza política.

Asimismo, también como precedentes, en la legislación especial de la década de los sesenta en Barcelona y Madrid, se producía un reconocimiento expreso de la existencia del personal directivos en estos municipios.

\section{NOTAS GENERALES DE LOS GOBIERNOS LOCALES EN LA CONSTITUCIÓN DE 1978}

El reconocimiento constitucional de los Gobiernos locales se contiene en el Título VIII, artículos 137 y 140. La Constitución del 1978 siguiendo nuestra tradición histórica dedica un escueto articulado expresa y específicamente a los Entes Locales, salvo la Constitución de 1812 las restantes han dedicado muy pocos artículos a la cuestión local. De esta forma el carácter escueto y elástico de los preceptos constitucionales sobre la autonomía local ha constituido un pretexto para no extraerles toda su eficacia normativa (García Roca, J. 2001).

De una visión de conjunto del Título VIII del texto del 78 evidenciamos que los municipios, definidos como entes públicos territoriales, se configuran como elemento básico en la organización territorial a partir de los cuales se estructura y vertebra territorialmente el Estado. En el resto del texto constitucional encontramos menciones expresas e implícitas a los entes locales a la hora de determinar a quién, y en qué términos, corresponde establecer el régimen jurídico local. El artículo 149.1.18aㅡ CE ${ }^{4}$, entre otras materias, atribuye al Estado la competencia exclusiva para establecer las bases del régimen jurídico de las Administraciones públicas. Por su parte, el artículo 148.1.2a CE habilita a las CCAA para asumir competencias en materia local, siempre que se incluya en sus respectivos Estatutos de Autonomía.

\footnotetext{
${ }^{4}$ El Artículo 149.1.18a CE incluye las siguientes materias de competencia exclusiva estatal: "El Estado tiene competencia exclusiva, entre otras materias para establecer las bases del régimen jurídico de las Administraciones públicas y del régimen estatutario de los funcionarios que, en todo caso, garantizarán a los administrados un tratamiento común ante ellas; el procedimiento administrativo común, sin perjuicio de las especialidades derivadas de la organización propia de las Comunidades Autónomas; legislación sobre expropiación forzosa; legislación básica sobre contratos y concesiones administrativas y el sistema de responsabilidad de todas las Administraciones públicas".
} 
Se configura así un modelo en el que legislan sobre régimen local tanto el Estado como las Comunidades Autónomas que hayan asumido en sus Estatutos competencias en la materia. Esta peculiar naturaleza bifronte de la legislación de régimen local hace que la determinación del contenido, alcance y extensión de las competencias locales, incluida la ordenación de su sistema directivo, sea el resultado de la intervención concurrente y no siempre armónica de las dos instancias territoriales superiores.

Esta configuración hace que la administración local presente una serie de rasgos y caracteres que la singularizan respecto de las otras dos administraciones territoriales: la administración estatal y la autonómica. Esta singularidad es consecuencia de su dependencia normativa respecto de estas otras administraciones. Singularidad que si unimos al debate directivo adquiere una mayor transcendencia y significación, y hace que se vuelva especialmente complejo y difícil de resolver dado el carácter representativo del gobierno local, como seguidamente analizamos.

En relación a la distribución de competencias en materia de régimen local, la Constitución atribuye al legislador básico la fijación de los principios básicos en orden a las competencias que deba reconocerse a las entidades locales, y al legislador autonómico la posibilidad de completar al amparo del 148.1 2. a CE lo establecido por el legislador básico en materia de régimen local $y$, todo ello, sin olvidar la función de los legisladores sectoriales competentes sobre las materias que de alguna u otra forma, también, incidan en las competencias o funciones municipales.

Es de destacar que todas las Comunidades autónomas han asumido competencias legislativas exclusiva o compartida en materia de régimen local. Los primeros Estatutos de autonomía, como el vasco o el catalán, confirieron a las respectivas comunidades autónomas la competencia exclusiva sobre régimen local sin perjuicio de lo establecido en el artículo 149.1.18 a de la Constitución -art. 10.4 Estatuto Autonomía del País Vasco de 1979 y art. 8 Estatuto Autonomía de Cataluña de 1979-. Otros estatutos de autonomía posteriores como el valenciano se expresan en términos similares ${ }^{5}$.

A partir de 2006 mediante la aprobación de nuevos estatutos de autonomía -especialmente los de Andalucía ${ }^{6}$, Aragón ${ }^{7}$ y Cataluña ${ }^{8}$ - se ensanchan las competencias autonómicas en materia de régimen local. Podemos afirmar que los Estatutos de Autonomía de segunda generación contienen una mayor densidad jurídica en materia local lo que ha producido también una mayor tensión entre la legislación básica estatal y los Estatutos de Autonomía (Pérez García, M. L., 2015).

Asistimos en la actualidad a una interpretación extensa del título competencial contenido en el artículo 149.1.18 CE, lo que ha permitido legislar con notable amplitud e intensidad en materia local al legislador estatal. Interpretación ésta que ha sido avalada por el Tribunal Constitucional en el sentido de considerar que las atribuciones estatutarias

\footnotetext{
${ }^{5}$ Ley Orgánica 5/1982, de 1 de julio, de Estatuto de Autonomía de la Comunidad Valenciana, en el artículo 31.8, se atribuye competencias exclusivas en "Régimen local. Sin perjuicio de lo que dispone el número dieciocho del apartado uno del artículo 149 de la Constitución".

${ }^{6}$ LO 2/2007, de 19 de marzo, de reforma del Estatuto de Autonomía para Andalucía.

${ }^{7}$ LO 5/2007, de 20 de abril, de reforma del Estatuto de Autonomía de Aragón.

${ }^{8}$ LO 6/2006, 19 de julio, de reforma del Estatuto de Autonomía de Cataluña.
} 
no pueden impedir el pleno desenvolvimiento de las competencias estatales incluidas en el artículo $149.1 \mathrm{CE}^{9}$.

En este sentido, la más reciente jurisprudencia constitucional parece ponderar que en materia local sólo caben competencias legislativas autonómicas de desarrollo, de esta forma la STC 161/2013, de 26 de septiembre, en su Fundamento jurídico tercero, recogiendo la doctrina constitucional anterior, entiende que:

“(i) en virtud del artículo 149.1.18 corresponde al Estado fijar los principios o bases relativos a los aspectos institucionales (organizativos y funcionales) y a las competencias de los entes locales; (ii) las bases estatales "tienen los dos cometidos de concretar la autonomía local constitucionalmente garantizada para establecer el marco definitorio del autogobierno de los entes locales directamente regulados por la Constitución, en primer lugar, y, en segundo lugar, de concretar los restantes aspectos del régimen jurídico básico de todos los entes locales que son, en definitiva, Administraciones públicas"; (iii) y las competencias autonómicas en materia de régimen local son de desarrollo de las bases estatales, y el título que en esta materia otorga al Estado el artículo 149.1.18 CE no ha desaparecido por la modificación estatutaria y la calificación de la competencia como exclusiva". ${ }^{10}$

Asimismo, no podemos olvidar que la Constitución no contiene una relación de materias sobre las que se atribuya de modo expreso competencia a los entes locales de manera que, en muchos casos, ha sido la jurisprudencia constitucional la que ha definido si corresponde al legislador estatal o al legislador autonómico atribuir competencias a los entes locales, en función de la distribución de competencias efectuada por el propio texto constitucional. En el supuesto de materias compartidas habrá de ser el legislador básico estatal quien establezca qué competencias corresponderán a las entidades locales, siempre con la limitación de garantizar la autonomía local y, todo ello, sin excederse para no invadir las competencias autonómicas ${ }^{11}$.

En suma podemos afirmar que el tratamiento que la Constitución española hace de las entidades locales no es ni tan amplio ni tan exhaustivo como el que se hace del régimen competencial de las Comunidades autónomas. Una vez garantizada de forma muy escueta la autonomía de los entes locales para la gestión de sus respectivos intereses, la concreción de su ámbito competencial se difiere al legislador ordinario estatal o autonómico en función de la materia y de acuerdo a la distribución constitucional de competencias.

\footnotetext{
${ }^{9}$ STC 31/2010, fundamento jurídico 59.

${ }^{10}$ Reiterando en las anteriores SSTC 103/2013, de 25 de abril, Fundamento jurídico núm. 4 y 143/2013, de 10 de julio.

${ }^{11}$ Tal y como aclaró la STC 214/89, fundamento jurídico núm. 3.
} 


\section{LA ORGANIZACIÓN MUNICIPAL EN LA LEGISLACIÓN BÁSICA DE RÉGIMEN LOCAL Y SU INCIDENCIA EN LA DIRECCIÓN PÚBLICA LOCAL.}

La regulación básica en materia de organización, competencias y recursos de los municipios se contiene en la Ley 7/1985, de 2 de abril, reguladora de las Bases del Régimen Local y sus modificaciones posteriores. Norma en la que el Estado concreta la garantía institucional de la autonomía local y que sirve como marco básico de actuación a las Comunidades autónomas, que encuentran en esta norma el límite a sus potestades legislativas en materia local en sus respectivos territorios.

En su redacción original, año 1985, la Ley mantenía sustancialmente el modelo histórico tradicional de Administración local española, especialmente por lo que a los municipios se refería, tanto en el sistema orgánico-funcional como en materia de competencias locales. Junto a esta organización se continuaba reconociendo la existencia de regímenes especiales de organización municipal. Estos regímenes especiales no se regulan directamente por la LRBRL, salvo las líneas esenciales del Concejo abierto, limitándose respecto a los regímenes especiales de Madrid y Barcelona, a declararlos vigentes en cuanto no se opusiesen o resultasen incompatibles con la propia ley básica.

Es de destacar que ya la legislación de régimen local previa a la Constitución de 1978, contemplaba la posibilidad de establecer un régimen especial de Carta para los municipios, que aunque no fue desarrollado, permitió la aprobación de dos Leyes especiales en 1960 y en 1963. Estas leyes establecieron los regímenes especiales de Barcelona y Madrid, respectivamente, y sin contener grandes innovaciones, reforzaban la figura de los Alcaldes, creaban la figura de los delegados de servicio, realizaba una división territorial del municipio en distritos y, permitía que estos municipios pudieran modificar su régimen tributario.

Sin embargo la ley básica de régimen local, todavía vigente, ha sido objeto de numerosas reformas parciales, reformas que han ido acomodándola a las profundas transformaciones sociales, económicas y culturales de los municipios españoles en las últimas décadas. Tres han sido estas reformas y todas ellas han tenido impacto en la configuración del espacio directivo local, como seguidamente analizamos.

\section{a) El pacto local y la revisión orgánico funcional local.}

La primera reforma de la LRBRL, impulsada en el marco del denominado Pacto Local, en el que abordar la cuestión del reparto del poder en la organización territorial del Estado, se concreta a través de la Ley 11/1999, de 21 de abril, de medidas para el desarrollo del Gobierno local.

Con esta primera reforma se revisa el modelo orgánico-funcional local modificando la distribución de funciones y competencias entre los distintos órganos necesarios del Ayuntamiento: Alcalde, Pleno y Tenientes de Alcalde.

Con esta reforma se refuerza el liderazgo del ejecutivo local ampliando la capacidad de los Alcaldes y Alcaldesas en la gestión ordinaria municipal con objeto de facilitar y agilizar el funcionamiento de la Administración municipal. Este fortalecimiento de su figura se compensa con un reforzamiento de los mecanismos de control del 
ejecutivo local por parte del Pleno municipal y sus comisiones, así como las funciones fiscalizadoras de la acción de gobierno. Es decir, se fortalecen las funciones directivas en la gestión municipal de los Alcaldes y, como contrapeso, se mejoran los mecanismos de control del Gobierno municipal que hace que deba responder ante el Pleno y la opinión pública por su gestión de Gobierno.

Los mecanismos de control del ejecutivo local se complementan con las modificaciones de otras leyes básicas, como la de la Ley Orgánica de régimen electoral general, para incidir en la moción de censura local ${ }^{12}$ e introducir en el ámbito local la cuestión de confianza ${ }^{13}$. Se introduce una nueva regulación simplificada de la moción de censura, automatizando la convocatoria del Pleno que debe discutirla. Y, por otra parte, se introduce la cuestión de confianza vinculada a proyectos concretos como son la aprobación de los presupuestos de la corporación, del reglamento orgánico, de las ordenanzas fiscales y la aprobación que pongan fin a la tramitación municipal de los instrumentos de planeamiento general en el ámbito municipal.

\section{b) La reforma de 2003 y la institucionalización de la organización directiva en las grandes ciudades.}

La segunda gran reforma de la LRBRL se produce con la Ley 57/2003, de 16 de diciembre, de medidas para la modernización del Gobierno local, que modificará el tradicional tratamiento jurídico uniforme de los municipios españoles, heredero del modelo continental de Administración local que preveía la existencia de un único régimen común para todos ellos (Ortega, 2000; Font, 2011).

Con esta reforma se introduce un nuevo Título $X$ a la Ley para establecer un régimen orgánico específico para aquellos municipios definidos por la norma como de gran población. El Título $X$ a la LRBRL establece un régimen orgánico específico para aquellos municipios con población superior a los 250.000 habitantes; las capitales de provincia de población superior a 175.000 habitantes; los municipios capitales de provincia, capitales autonómicas o sede de instituciones autonómicas; y los municipios cuya población supere los 75.000 habitantes que presenten circunstancias económicas, sociales, históricas o culturales especiales, si bien en los dos últimos casos se exige que así lo decidan la Asamblea legislativa de la Comunidad Autonómica respectiva ${ }^{14}$.

Se introduce, así pues, un nuevo régimen de organización y funcionamiento distinto al aplicable a los municipios de régimen común. Los municipios de las grandes ciudades cuentan con un mayor número de órganos necesarios, al Pleno, al Alcalde y a los

\footnotetext{
${ }^{12}$ Artículo 197 redactado por Ley Orgánica 8/1999, 21 abril, de modificación de la Ley Orgánica 5/1985, de 19 de junio, del Régimen Electoral General. Modificado posteriormente por el apartado cincuenta y siete del artículo único de la LO 2/2011, de 28 de enero, por la que se modifica la Ley Orgánica 5/1985, de 19 de junio, del Régimen Electoral General.

${ }^{13}$ Artículo 197 bis, introducido por Ley Orgánica 8/1999, 21 abril, de modificación de la Ley Orgánica 5/1985, de 19 de junio, del Régimen Electoral General.

${ }^{14}$ Además, son de aplicación las normas contenidas en los capítulos II y III de este título a los Cabildos Insulares Canarios de Islas cuya población sea superior a 175.000 habitantes, y a los restantes Cabildos Insulares de Islas cuya población sea superior a 75.000 habitantes, siempre que así lo decida mediante Ley el Parlamento Canario a iniciativa de los Plenos de los respectivos Cabildos.
} 
Tenientes de Alcalde, -establecidos también para el régimen común- se añaden las Comisiones del Pleno y la Junta de Gobierno Local ${ }^{15}$; se hace necesaria la división del municipio de gran población en distritos municipales como instrumento para desarrollar políticas de proximidad y participación en los municipios altamente poblados, tanto desde la perspectiva de la desconcentración de funciones, como la de la participación ciudadana, lo que obliga a sus Ayuntamientos a establecer un porcentaje mínimo de recursos que serán gestionados directamente por los distritos; se profundiza en los mecanismos de participación ciudadana creando un órgano con el que puedan participar los vecinos y defender sus derechos; por último, en estos municipios se diferencia entre órganos superiores y directivos en el seno de la organización municipal.

En líneas generales, la organización municipal en las grandes ciudades se basa en una distribución de funciones entre el Pleno, el Alcalde y la Junta de Gobierno, distinta a la que se prevé para los municipios de régimen común. De esta forma, la norma básica permite que los municipios de las grandes ciudades puedan diseñar una organización en la que coexistan, de un lado; el Alcalde, el cual es titular del poder ejecutivo y, al mismo tiempo, presidente del órgano que controla al poder ejecutivo; el Pleno; y de otro, una Junta de Gobierno Local parecida a un ejecutivo de corte presidencialista (Santamaría, 2004, 637). Finalmente, el control de esta organización ejecutiva, así como el debate de las grandes políticas locales, y la adopción de acuerdos reservados a la competencia del Pleno municipal configurado como un órgano mixto (Palomar, 2005, 68), que no sólo desarrolla funciones típicas del control del ejecutivo, sino también funciones de naturaleza esencialmente administrativa.

Como resultado estos municipios cuentan con un sistema que podemos calificar de cuasi parlamentario al establecer la legislación básica una más clara separación entre el órgano representativo municipal -Pleno-, y los órganos ejecutivos, tanto a nivel individual -Alcalde-, como colegiado -Junta de Gobierno Local-. Sin embargo, incluso para estos municipios, no es perfectamente extrapolable en comparativa, la división de poderes legislativo/ejecutivo que se produce en el nivel estatal o autonómico.

El Pleno municipal, en los municipios de gran población, refuerza su posición como órgano en cuyo seno se debaten y adoptan las grandes decisiones estratégicas del municipio, pudiendo incluso, delegar sus funciones resolutorias en las Comisiones del Pleno; sin embargo, la legislación básica limita al mismo tiempo sus funciones ejecutivas o administrativas.

A su vez, en estos municipios se refuerza la posición de los Alcaldes como principal órgano de dirección de la política, el gobierno y la Administración municipal, ostentando, junto a las funciones simbólicas, otras atribuciones ejecutivas. Sin embargo, el Alcalde en

\footnotetext{
${ }^{15}$ La Junta de Gobierno local que también existe en los municipios de régimen común que cuenten con más de 5000 habitantes y en los de menos, cuando así lo disponga su Reglamento Orgánico o así lo acuerde el Pleno de su Ayuntamiento. Sin embargo, en los municipios de régimen común no es un órgano necesario como si sucede en los municipios de gran población. Es de destacar que la reforma de 2003 cambia la denominación de este órgano Comisión de Gobierno, por la de Junta de Gobierno. Esta modificación tiene por objeto profundizar en el carácter ejecutivo y de gobierno de este órgano, frente a las conocidas como Comisiones municipales, que históricamente carecían de carácter resolutorio, con funciones únicamente de deliberativas e informadoras, a las que se unían funciones de seguimiento.
} 
los municipios de gran población cuenta con menos atribuciones gestoras o ejecutivas que el Alcalde de régimen común. Muchas de las funciones ejecutivas y gestoras de estas corporaciones son asignadas por la legislación básica a la Junta de Gobierno local, formada por los Concejales designados libremente por el Alcalde, el cual, también podrá cesarlos libremente, cuya existencia es obligatoria en su organización municipal. La Junta se constituye como órgano colegiado esencial de colaboración en la dirección política y, para ello se le dota de amplias funciones de naturaleza ejecutiva ${ }^{16}$.

El artículo 126.2, párrafo segundo, inciso primero LRBRL, en su redacción inicial preveía que hasta un tercio, como máximo, de sus miembros, excluido el Alcalde, pudieran ser personas que no ostentarán la condición de Concejal. Esta posibilidad fue declarada inconstitucional por el Tribunal Constitucional ${ }^{17}$, por lesionar el principio democrático representativo de los gobiernos locales. Todo ello sin perjuicio de la libertad de organización de los Ayuntamientos en el funcionamiento de la actividad de asesoramiento a los órganos de Gobierno que puedan determinar sus reglamentos orgánicos, en el marco de la legislación aplicable.

Finalmente, establece que estos municipios un modelo de organización que se concreta en la necesidad de establecer grandes áreas de gobierno, en ellas se introduce, un nivel directivo responsable de la coordinación y seguimiento en el diseño de las políticas municipales y su implementación por los órganos administrativos de la Corporación. En el ejecutivo local de las grandes ciudades la ley básica distingue entre Órganos superiores y Órganos directivos -artículo 130 LRBRL-. A los órganos superiores conformados por el Alcalde y los miembros de la Junta de Gobierno Local, les corresponde hacer la política municipal y las principales funciones ejecutivas. A los Órganos directivos, conformados por distintas figuras -coordinador general, director general, secretario general y secretario adjunto de la junta de gobierno, interventor general, directivo de organismos autónomos y de entidades públicas empresariales-, les corresponde la gestión, la puesta en práctica y coordinación de los programas de gobierno definidos por los órganos superiores.

Este diseño institucional permite diferenciar la actividad política de la actividad de gestión e implementación administrativa. De esta forma, al ejecutivo local en sentido

\footnotetext{
${ }^{16}$ Esta configuración de la Junta de Gobierno se fundamenta en la Ley de modernización para equiparar el gobierno local español al modelo europeo de gobierno local reflejado en la Carta europea de la autonomía local, cuyo artículo 3.2 prevé que los órganos electivos colegiados puedan disponer de órganos ejecutivos responsables ante ellos mismos.

${ }^{17}$ La Sentencia TC Pleno 103/2013, de 25 de abril, declara inconstitucional y nulo el artículo 126.2, párrafo segundo, inciso primero, en los términos establecidos en el Fundamento Jurídico 6. ${ }^{\circ}$ que declara que la: "inconstitucionalidad se limita única y exclusivamente a la facultad que se reconoce al Alcalde para nombrar como miembros de la Junta de Gobierno a personas que no ostenten la condición de concejales, pero no se extiende a la regulación de dicho órgano. Pero antes de pronunciar el fallo de inconstitucionalidad y consiguiente nulidad a que conduce nuestro razonamiento, es preciso determinar cuál es el alcance y efectos que corresponde atribuir a dicho fallo y, en tal sentido, debemos establecer que han de considerarse situaciones consolidadas no susceptibles de ser revisadas con fundamento en esta Sentencia las nacidas con anterioridad a la fecha de su publicación. Y todo ello sin perjuicio de la libertad de organización de los Ayuntamientos del funcionamiento de la actividad de asesoramiento a sus órganos de gobierno, en el marco de la legislación aplicable."
} 
estricto -Alcalde y Junta de Gobierno- le corresponde hacer política, confiándose la gestión municipal a la alta Administración local, es decir, a los órganos directivos y, también en su caso, a determinados puestos de la organización con contenido directivo establecido en el Reglamento orgánico municipal.

Llegados a este punto y en coherencia con el principio de autonomía local, este modelo no puede entenderse de aplicación obligatoria ya que el esquema organizativo previsto en el artículo 123.1.B.c) ${ }^{18}$ es facultativo, en el sentido interpretado por el Tribunal Constitucional que en la STC 103/2013, de 25 de abril, declara constitucional el artículo 130.1.B, en la redacción dada por el artículo primero de la 57/2003, de 16 de diciembre, siempre que se interprete de acuerdo con lo señalado en el FJ 5. J), que declara:

"el precepto impugnado admite una interpretación conforme [...], en la medida en que se limita a relacionar, dentro de los órganos directivos, los titulares de órganos que pertenecen a la organización básica de los municipios de gran población, no impide a las Leyes autonómicas que completen, dentro de su competencia para regular la organización complementaria, este elenco de órganos directivos".

Por tanto, cada municipio puede optar por aplicar esa forma de organización, creando dichos órganos y delegando en los mismos determinadas competencias; o bien, puede optar por no aplicarlo, manteniendo su modelo tradicional de organización administrativa sin nivel directivo o introduciendo un modelo organizativo directivo diferente al establecido en la ley básica; sin embargo, hay determinadas normas organizativas contenidas en el Título $X$ de la LRBRL que si son imperativas.

Sintetizando, pues, con esta reforma se contempla por vez primera la posibilidad de que los municipios de gran población puedan dotarse de órganos directivos, previsión que no contemplada para la organización ejecutiva de los municipios del régimen común.

\section{b) Equilibrio presupuestario y configuración espacio directivo local.}

La tercera y última gran reforma de la LRBRL se concreta con la Ley 27/2013, de 27 de diciembre, de racionalización y sostenibilidad de la Administración Local (LRSAL, en adelante). Tras la reforma del artículo 135 de la Constitución española, en su nueva redacción dada en $2011^{19}$ se consagra la estabilidad presupuestaria como principio rector

\footnotetext{
${ }^{18}$ El artículo 123.1. B, en su apartado c), establece que corresponden al Pleno, entre otras, las siguientes atribuciones: “c) La aprobación y modificación de los reglamentos de naturaleza orgánica. Tendrán en todo caso naturaleza orgánica: [...] la determinación de los niveles esenciales de la organización municipal, entendiendo por tales las grandes áreas de gobierno, los coordinadores generales, dependientes directamente de los miembros de la Junta de Gobierno Local, con funciones de coordinación de las distintas Direcciones Generales u órganos similares integradas en la misma área de gobierno, y de la gestión de los servicios comunes de éstas u otras funciones análogas y las Direcciones Generales u órganos similares que culminen la organización administrativa, sin perjuicio de las atribuciones del Alcalde para determinar el número de cada uno de tales órganos y establecer niveles complementarios inferiores[...]"

${ }^{19}$ La segunda y última reforma constitucional de 2011 después de la realizada en 1992, modifica el artículo 135 CE introduciendo en el texto constitucional el concepto de estabilidad presupuestaria y la prioridad del pago de la deuda pública en los presupuestos generales. La propuesta de reforma fue realizada el 23 de agosto de 2011 y contó con el apoyo de los dos partidos mayoritarios PP y PSOE y, del grupo UPN. Dado que
} 
de la actuación de todas las Administraciones Públicas ${ }^{20}$, para las Entidades locales implica contar con equilibrio presupuestario. Con este propósito, la LRSAL retorna al modelo de control económico-financiero de las entidades locales por Administraciones territoriales superiores y, adapta la organización y funcionamiento de la Administración locales a la nueva realidad económica financiera del Estado Español.

En la Exposición de motivos la Ley manifiesta perseguir varios objetivos básicos. En primer lugar, clarificar las competencias municipales para evitar duplicidades con las competencias de otras Administraciones, de forma que se haga efectivo el principio una Administración una competencia. En segundo lugar, racionalizar la estructura organizativa de la Administración local de acuerdo con los principios de eficiencia, estabilidad y sostenibilidad financiera. En tercer lugar, garantizar un control financiero y presupuestario más riguroso de las entidades locales y de sus entidades dependientes. Y, por último, favorecer la iniciativa económica privada evitando con ello la intervención administrativa local.

Por lo que se refiere a la configuración del espacio directivo local con esta reforma se introdujeron importantes previsiones. En primer lugar, en relación a la dirección política incide sobre el régimen retributivo de los miembros de las corporaciones locales y limitación del número de cargos públicos con dedicación exclusiva. Se introducen dos nuevos artículos -75 bis y 75 ter- con importantes novedades en esta materia. Por un lado, se atribuye a las futuras Leyes de Presupuestos Generales del Estado la obligación de determinar anualmente el límite máximo total que pueden percibir los miembros de las Corporaciones Locales por todos los conceptos retributivos y asistencias, atendiendo a la naturaleza de la Corporación Local y a su población y siguiendo los criterios de una tabla comparativa que establece la propia Ley y que toma como referencia las retribuciones de un Secretario de Estado. Por otro, no se permite a los miembros de las Corporaciones Locales de menos de 1000 habitantes tener dedicación exclusiva aunque, excepcionalmente, podrán contar con una dedicación parcial dentro de los límites máximos que señale la Ley de Presupuestos del Estado.

Al mismo tiempo, se fija el número máximo de cargos con dedicación exclusiva por Ayuntamiento, en función de criterios poblacionales. Así, los municipios de menos de 1000 habitantes no podrán contar con ninguno, hasta 2000 habitantes, un miembro máximo, hasta 3000 habitantes, dos miembros y hasta 10.000 habitantes, tres miembros, continuando la escala en función del número de habitantes.

En segundo lugar, introduce un artículo 104 bis para regular el personal eventual, estableciéndose unos límites al número de puestos de trabajo de personal eventual en las plantillas de los Ayuntamientos y de las Diputaciones Provinciales en función del número

los grupos parlamentarios firmantes tenían conjuntamente, en dicha legislatura, más del $90 \%$ de diputados y senadores, y al tratarse de una reforma por proceso ordinario, no fue necesario un referéndum; tampoco fue solicitado por un $10 \%$ de los representantes de una de ambas cámaras, dentro del plazo previsto que concluyó el 26 de septiembre de 2011. La entrada en vigor de parte del artículo, sin embargo, se demorará hasta el 2020.

${ }^{20}$ En desarrollo de este precepto constitucional se aprobó la Ley Orgánica 2/2012, de 27 de abril, de Estabilidad Presupuestaria y Sostenibilidad Financiera, que exigía nuevas adaptaciones de la normativa básica en materia de Administración local para la aplicación de los principios de estabilidad presupuestaria, sostenibilidad financiera o eficiencia en el uso de los recursos públicos locales. 
de habitantes, teniendo que publicar semestralmente en la sede electrónica y en el Boletín Oficial de la Provincia el número de los puestos de trabajo reservados a personal eventual. Además el Presidente de la Entidad Local informará trimestralmente al Pleno del cumplimiento de esta obligación.

Finalmente, en relación al objeto de nuestro trabajo la dirección pública profesional introduce, por fin, una referencia explícita al personal directivo de Diputaciones, Cabildos y Consejos Insulares. De esta forma el artículo 32 bis establece que el nombramiento del personal directivo de estas concretas entidades locales deba efectuarse de acuerdo a criterios de competencia profesional y experiencia entre funcionarios de carrera del Estado, de las Comunidades Autónomas, de las Entidades Locales o con habilitación de carácter nacional del subgrupo A1, con la salvedad de que si el Reglamento Orgánico permite que en atención a las características específicas de las funciones de estos órganos directivos, podrá nombrarse a alguien que no reúna dicha condición de funcionario. De esta forma, se introducen también requisitos de acceso a los puestos directivos de las entidades locales provinciales.

Sin embargo, la LRSAL no se aplica de manera uniforme en todos los municipios españoles. Durante su debate parlamentario se fueron incorporando cláusulas de descuelgue de una mayor o menor importancia para algunas Comunidades Autónomas (VELASCO, 2014, 4), entre ellas: Aragón, Baleares, Canarias, Navarra y País Vasco ${ }^{21}$; y también para las ciudades autónomas: Ceuta y Melilla ${ }^{22}$. También recoge una disposición adicional, la quinta, para dos municipios: Barcelona y Madrid ${ }^{23}$. Siguiendo a Jiménez Asensio $(2014,300)$ la LRSAL incorpora inconscientemente el principio de diferenciación a la regulación del ámbito local de gobierno, y según su análisis, esta diferenciación atraviesa todo el texto legal, aunque en algunos casos con manifestaciones expresadas de forma explícita y, en otros de manera menos evidente. Esta diferenciación en la aplicación de la ley se proyecta en tres dimensiones: a) en función de la aplicabilidad territorial; b) en función del tipo de entidad local, de sus dimensiones o del ente instrumental al que afecte y c) en la aplicabilidad de determinadas medidas sujetas a condicionalidad, especialmente el cumplimiento o incumplimiento de los objetivos de estabilidad presupuestaria y sostenibilidad financiera.

\footnotetext{
${ }^{21}$ En relación a los regímenes especiales de determinadas CCAA fue objeto (apartado 7o) del Informe acerca del contenido autonómico del Proyecto de Ley de racionalización y sostenibilidad de la Administración Local por la Comisión General de las Comunidades Autónomas en la Ponencia parlamentaria, en su sesión celebrada el día 26 de noviembre de 2013, Vid. Boletín Oficial de las Cortes Generales, Senado, núm. 277, de 29 de noviembre de 2013, pág. 22 y ss.

${ }^{22}$ Mientras la DA 1a LRSAL establece una aplicación singularizada para el País Vasco la DA 2a hace lo mismo para la Comunidad Foral de Navarra. De forma más reducida, la DA 3a.2 LRSAL particulariza la aplicación en Aragón, por su "régimen especial de organización institucional”, es decir, la división estatutaria comarcal. En Ceuta y Melilla, la DA 4a también introduce algunas particularidades. Por último, la DA 16ạ LRSAL preserva la legislación específica de aplicación a los consejos insulares baleares y a los cabildos canarios.

${ }^{23}$ La Disposición adicional quinta. Sobre los Regímenes especiales de Madrid y Barcelona, establece que las disposiciones de la LRSAL son de aplicación a los municipios de Madrid y Barcelona, sin perjuicio de las particularidades de su legislación específica y con estricta sujeción a los principios de estabilidad presupuestaria y sostenibilidad financiera.
} 
Así pues, con esta última reforma se limitan el número de cargos electos con dedicación exclusiva, el número de personal eventual y define al personal directivo profesional en las Diputaciones provinciales, lo que ya ha ocasionado repercusiones en nuestro objeto de nuestro estudio, ya que la posibilidad de dedicación de los cargos electos y cargos políticos, en su actividad de gestión y dirección en el aparato administrativo local, se ha visto mermada. Lo que seguro favorecerá a más largo plazo la mejor dotación de personal directivo en la gestión de la entidad local y favorecerá el desarrollo de un verdadero espacio directivo profesional en nuestras entidades locales, municipios y Diputaciones provinciales.

\section{5. ÁMBITOS DE LA DIRECCIÓN PÚBLICA EN LA ORGANIZACIÓN LOCAL.}

A la vista de la evolución del régimen legal analizado en el apartado anterior, la legislación básica en materia de régimen local establece tres sistemas de organización de los municipios españoles: el régimen general para los municipios de régimen común; el régimen de los municipios de gran población, y los regímenes especiales del concejo abierto y de las ciudades de Barcelona y Madrid ${ }^{24}$. Tanto la normativa reguladora de los municipios de régimen común, como la de los municipios de gran población y, los sujetos al Concejo abierto, está contenida en la Ley 7/1985, de 2 de abril. Por su parte las ciudades de Barcelona y Madrid, se regulan por sus leyes especiales. Todo ello sin olvidar la normativa autonómica en la materia.

Trasladado el esquema al espacio directivo local realizada por el profesor Jiménez Asensio (1996) y tras las sucesivas reformas de la legislación básica de régimen local, podemos distinguir, en nuestras administraciones locales, hasta tres grandes grupos de funciones directivas: el primero, la dirección estrictamente política, integrada por los electos locales; el segundo, la dirección de carácter político y profesional, que se corresponde con las figuras de gerente, coordinador de área, director general o cargos asimilables en los municipios de gran población y, las ciudades de Madrid y Barcelona; y, el tercer grupo, que corresponde a la dirección burocrática, estrictamente profesional y que se corresponde con las direcciones de servicios y asimilados. Estos diferentes ámbitos de la dirección pública cuentan, como repararemos seguidamente, con unas características específicas según sea su tipo de organización municipal.

En consecuencia la cuestión que se nos plantea en este punto es determinar si la distinta organización municipal establecida en la legislación básica local implica o no diferencias sustantivas en la dirección pública de las entidades municipales españolas.

\section{Dirección política}

La dirección política en el ámbito local está integrada, exclusivamente, por los electos locales, es decir, por el Alcalde y los Concejales que forman parte de la Junta de Gobierno Local.

${ }^{24}$ Leyes $1 / 2006$, de 13 de marzo y 22/2006, de 4 de julio respectivamente. 
Para los municipios de régimen común la Ley realiza un reparto de funciones y competencias entre los órganos municipales que hace que el Alcalde, acumule y ejerza prácticamente todas las facultades ejecutivas importantes en el seno de la organización municipal. El Alcalde o Alcaldesa personifica el principal órgano de dirección política y, le corresponde el gobierno y la administración municipal. Entre otras funciones directivas dirige los servicios municipales, ostenta la jefatura del personal, cuenta con capacidad sancionadora, aprueba proyectos, contratos y servicios que no superen determinada cuantía.

En los municipios de régimen común, al no existir una categoría de órganos directivos en la organización municipal, unido a que el Alcalde sólo puede delegar sus facultades ejecutivas en Concejales o Tenientes de Alcalde, hace que en la práctica ejerza el liderazgo, de hecho, de la política municipal y, que a su vez, desempeñe las principales funciones directivas en la administración municipal.

En cambio, para los municipios de gran población se distingue en su estructura organizativa entre órganos superiores y órganos directivos. Los órganos superiores estarían conformados por los electos locales, es decir, por el Alcalde y los Concejales que forman parte de la Junta de Gobierno Local al estilo de un ejecutivo local (artículo 130 LRBRL). Ahora bien, esta organización hace que el Alcalde o Alcaldesa de las grandes ciudades cuente con menos atribuciones gestoras o ejecutivas que sus homónimos de régimen común.

Además, en la organización establecida para las grandes ciudades por el Título $\mathrm{X}$ LRBRL, se permite la delegación de funciones ejecutivas de los órganos superiores en los órganos directivos. Lo que hace que en la práctica los directivos públicos locales puedan ejecutar planes políticos de la corporación municipal, asumiendo no sólo funciones de ejecución, sino también, responsabilidades en el desarrollo de los proyecto de gobierno. Sin embargo, el Alcalde no pueda delegar todas sus funciones ejecutivas en los órganos directivos; ya que, es indelegable no sólo en los órganos directivos, sino en cualquier otro órgano de la corporación, la dirección de la política, el gobierno y la administración municipal, sin perjuicio de la acción colegiada de colaboración en la dirección política atribuidas por Ley a la Junta de Gobierno.

La posibilidad de abrir este espacio político en los municipios de gran población a personas no electas, permitiendo que hasta un tercio de los miembros de la Junta de Gobierno puedan ser designados por los Alcaldes entre personas no electas, como hemos visto fue revisada por el Tribunal Constitucional, cerrando la puerta a que profesionales no elegidos democráticamente pudieran incorporarse a los órganos superiores de la entidad local.

En conclusión, la dirección política en el caso de los municipios de gran población se corresponderá con los "órganos superiores", en cambio, para la mayoría de las corporaciones locales que se sujetan a las previsiones del régimen común, aún sin la consideración de órgano, la dirección política será desarrollada fundamentalmente por el Alcalde o la Alcaldesa en la organización municipal. 


\section{Dirección de carácter profesional.}

El espacio de la dirección de carácter profesional es un espacio indefinido que en el ámbito local se formaliza jurídicamente, aunque sea de forma parcial, a través de los "órganos directivos" y sus equivalentes en el régimen especial de las ciudades de Madrid y Barcelona; además, de los directivos de Organismos autónomos y Entidades públicas empresariales, para la administración institucional.

En las administraciones dependiente en el caso de los organismos autónomos se corresponde con el titular del máximo órgano de dirección que podrá ser un funcionario de carrera o laboral, y que en los municipios señalados en el título $\mathrm{X}$, tendrá la consideración de órgano directivo.

En la organización municipal de las grandes ciudades los órganos directivos comprende desde los puestos de coordinador general de área o Concejalía a los puestos de director general $u$ órganos similares que culminan la organización administrativa dentro de cada una de las grandes áreas o Concejalías hasta los órganos directivos con un mayor componente técnico (jurídico o económico). En Madrid se reproducen prácticamente los órganos directivos previstos para los municipios de gran población, y en Barcelona se corresponderá con gerentes y vicegerentes.

Los titulares de estos órganos municipales participan en la definición de programas y formulación de políticas y/o en la gestión de los programas públicos municipales; dirigen la organización y las personas a su cargo con una cierta autonomía operativa; y, finalmente, se responsabilizan de la intermediación con los intereses sociales organizados. Esta última función, como intermediación es muy importante ya que el contacto de la dirección estrictamente política con la burocracia profesional se produce a través de este escalón de directivos también profesionales. Por tanto, se convierten en los interlocutores de los electos locales con el resto de los empleados públicos locales, lo que se traduce que en ocasiones sean los encargados de realizar funciones de negociación en el seno de la organización.

Observar que las sucesivas reformas legislativas de régimen local aplicable a la dirección de carácter profesional han ido equiparando su régimen de incompatibilidades a las previsiones recogidas para los altos cargos de la Administración General del Estado. Estas reformas han hecho que a pesar de no existir en los Ayuntamientos altos cargos al estilo de la administración estatal y, no ser posible nombrar miembros de los órganos superiores entre personas no electas, se hayan ido dando pasos para equiparar el régimen de incompatibilidades del personal directivo profesional local con el régimen de incompatibilidades establecido para los altos cargos de la $\mathrm{AGE}^{25}$. Equiparación que también realiza la jurisprudencia considerando que ${ }^{26}$ :

"El artículo 130 de la Ley 7/1985 establece como órgano directivo a los directores generales, y como ya dijimos en nuestra sentencia de 30 de junio de 2008, este personal directivo no tiene que constar en la RPT, ni sus funciones o condiciones de

\footnotetext{
${ }^{25}$ En concreto, la ley 8/2007 de 28 de mayo añadió una Disposición adicional 15a a la Ley de Bases de Régimen Local estableciendo esta previsión.

${ }^{26}$ Sentencias del Tribunal Superior de Justicia de Asturias, de 30 de junio de 2008 y de 15 de mayo de 2009
} 
trabajo han de ser objeto de negociación colectiva...pudiendo ser nombrados sin necesidad de convocatoria pública y cesados libremente por la Junta de Gobierno local, por lo que es lógica su consideración como una suerte de altos cargos"

En general el nombramiento y cese de los titulares de los órganos directivos (excepto para los habilitados nacionales) en las grandes ciudades es una atribución de la Junta de Gobierno. Los ocupantes de estos puestos directivos estén sometidos a una doble tensión dentro de la organización: de un lado la presión política, encargada de su nombramiento, y que a falta de una regulación clara, hace que la provisión de estos puestos directivos se produzca en función de la confianza política del proponente; y por otra parte, a la tensión profesional, dado que habitualmente desempeña un trabajo con un fuerte contenido técnico-profesional, en la primera línea de la estructura burocrática administrativa.

\section{Dirección burocrática.}

La dirección burocrática agrupa al personal de la administración local que ocupa las direcciones administrativas inferiores y se corresponde con las direcciones de servicio, de sección o de negociado. Este estrato directivo está constituido por el conjunto de puestos que en la Relación de puestos de trabajo de cada corporación local desempeñan tareas materiales de gestión o directivas pero que no reciben el calificativo de órgano directivo.

En todos los municipios con independencia de su organización "común" o "especial" encontraremos este tipo de dirección estrictamente burocrática creada a través del reglamento orgánico y de la relación de puestos de trabajo de cada corporación local.

En el contenido de las funciones de estas direcciones burocráticas prima la capacidad técnica y el desarrollo de competencias directivas como dirigir equipos, diseñar proyectos o evaluar programas. Las funciones exactas de estos puestos se concretan en la Relación de puestos de trabajo que elaborará cada Administración local haciendo efectivas sus competencias de autoorganización local.

\section{LOS MUNICIPIOS DE RÉGIMEN COMÚN Y LA CUESTIÓN DIRECTIVA.}

En estos municipios la normativa básica atribuye al Alcalde las facultades ejecutivas más importantes $y$, lo que es más significativo para nuestro estudio, el ejercicio de las principales competencias y funciones directivas en el seno de la organización municipal. Competencias ejecutivas que sólo puede delegar en algún otro Concejal, no en un empleado municipal. En esta situación, en estos municipios es la Alcaldía la que ejerce el liderazgo de la política municipal y, a su vez, desempeña las principales funciones directivas del Ayuntamiento.

El Alcalde en estos municipios a diferencia de otros sistemas de Gobierno local, concentra la autoridad ejecutiva municipal: encabeza el gobierno y la Administración; impulsa y dirige los servicios municipales; es jefe de personal; ejerce la potestad sancionadora; aprueba proyectos, contratos y servicios que no superen determinada cuantía; etc. Puede nombrar entre los Concejales a uno o varios tenientes de Alcalde, en 
los que puede delegar determinadas atribuciones. Alcalde y tenientes de Alcalde ejercen las máximas funciones ejecutivas de la Corporación. De hecho, ningún expediente empieza o finaliza en una Administración local de este tipo sin la firma de uno de estos representantes electos.

En los municipios con más de 5.000 habitantes, y en aquellos donde así lo disponga su Reglamento orgánico o lo establezca el Pleno, además se constituye una Junta de Gobierno Local, presidida por el Alcalde e integrada por un número de Concejales no superior a un tercio del total, nombrado y separado libremente por aquél. La Junta de Gobierno asiste al Alcalde en sus funciones, así mismo, la Junta también puede desempeñar aquellas funciones que le sean delegadas por otros órganos, incluido el Alcalde. En estos casos, la Junta de Gobierno también realiza funciones ejecutivas, iniciando y finalizando expedientes administrativos.

Si bien el articulado de la norma básica no prevé ni formal ni explícitamente órganos directivos para estos municipios, reconoce la existencia de directivos públicos en estas corporaciones al introducir un régimen de incompatibilidades específico para el personal directivo, de aplicación a todos los municipios con independencia de su régimen de organización. La Disposición adicional decimoquinta de la $\mathrm{LRBRL}^{27}$, al regular el régimen de incompatibilidades y declaraciones de actividades y bienes de los directivos locales y otro personal al servicio de las entidades locales, señala que:

“... A estos efectos, tendrán la consideración de personal directivo los titulares de órganos que ejerzan funciones de gestión o ejecución de carácter superior, ajustándose a las directrices generales fijadas por el órgano de gobierno de la Corporación, adoptando al efecto las decisiones oportunas y disponiendo para ello de un margen de autonomía, dentro de esas directrices generales...".

Por tanto, nos preguntamos si, como señala la norma, existen funciones de gestión o ejecución de carácter superior también en los municipios de régimen común: quién desarrolla estas funciones en estos municipios.

Dado que la LRBRL no identifica a estos directivos públicos locales su determinación sólo es posible si consideramos que la cualidad de personal directivo en los municipios de régimen común, la confiere la función desarrollada por este tipo de personal y no la denominación de órgano (Jiménez Asensio, 1998, 143). Es decir, al contrario de lo que ocurre en la Administración estatal y autonómica, en los municipios de régimen común debe manejarse un concepto de directivo público material o sustantivo. Un concepto éste, en el que el directivo público no se identifica, ni equivale al titular de un órgano formalmente calificado como tal por la norma, sino con el individuo que, en cualquiera de las categorías de personal al servicio de la corporación conforme al Título VII de la ley y del personal al servicio de la Organismos autónomos y Entidades públicas empresariales reguladas en el artículo 85 bis de la LRBRL, desempeña, efectivamente, funciones directivas (Maeso, 2011, 363).

\footnotetext{
${ }^{27}$ Disposición adicional decimoquinta introducida por la disposición adicional 9.5 de la Ley 8/2007, 28 de mayo, del suelo y, por disposición adicional 9.5 del R.D. Legislativo 2/2008, de 20 de junio, por el que se aprueba el texto refundido de la ley de suelo.
} 
No cabe duda de que en los municipios de régimen común existen y se desarrollan, al menos materialmente, funciones directivas. Estas necesidades de personal directivo son cubiertas mediante el tradicional recurso al personal eventual o mediante funcionarios ocupando puestos de libre designación (Nieto, 1984).

Hay que hacer notar que en estos municipios, la situación de la dirección pública prácticamente no ha cambiado desde los años ochenta; sin embargo, la creación de una Administración institucional local y la multiplicación de empresas públicas locales de capital municipal o, en su caso, con aportación mayoritaria del municipio, ha permitido la creación de una función directiva profesional en el seno de los gobiernos locales. A través de los artículos 85 bis y ter, tras la reforma de $2003^{28}$, se reconoce la existencia de directivos locales en los organismos autónomos, entidades empresariales y empresas locales, esta previsión también es aplicable a los municipios de régimen común, aunque sin la consideración de órgano directivo.

De esta forma, mientras que la legislación básica no reconoce la existencia de directivos locales en la organización municipal, sí prevé que sus organismos autónomos y entidades públicas empresariales dependientes de la entidad local puedan, a través de sus estatutos, determinar sus máximos órganos de dirección, ya sean unipersonales o colegiados, así como su forma de designación. Los Estatutos de la entidad pueden establecer que el titular del máximo órgano de dirección pueda ser funcionario de carrera o laboral de las Administraciones públicas o un profesional del sector privado, titulados superiores en ambos casos, y con más de cinco años de ejercicio profesional en el caso de procedencia del sector privado del candidato a directivo público local a una de las Administraciones dependientes de la Administración local.

A esta indefinición en la creación de un espacio directivo en los municipios de régimen común se une el que, en estos municipios, el Alcalde sólo puede delegar sus funciones ejecutivas en los Concejales, lo que imposibilita la asunción de estas funciones por directivos o gerentes. Esta situación dificulta todavía más el desarrollo en estas entidades de un espacio directivo profesional. Sólo el Alcalde y los Concejales electos, es decir, los políticos locales, disponen de competencias propias, haciendo que en la práctica sean los encargados de desempeñar en la práctica las principales funciones directivas en estas entidades locales.

Todo ello hace, que en los municipios de régimen común sólo podamos encontrar una dirección burocrática en la que prima la capacidad técnica, salvo en su Administración institucional en que si se prevé una dirección profesional.

Sin embargo, no debemos olvidar que la dirección burocrática es la única dirección pública presente en los municipios de régimen común pero al carecer de consideración de órganos directivos $y$, ante la imposibilidad de que los cargos representativos puedan delegar sus funciones directivas en el personal del Ayuntamiento; produce que en la práctica sea la dirección burocrática la encargada de dirigir equipos, diseñar proyectos o evaluar programas, lo que ciertamente, genera en estos municipios graves tensiones con la dirección política en el desarrollo del propio funcionamiento de la entidad.

\footnotetext{
${ }^{28}$ Artículos 85 bis y 85 ter introducidos por el apartado 3 del artículo primero de Ley 57/2003, de 16 de diciembre, de medidas para la modernización del gobierno local.
} 
Finalmente, entendemos que la falta de regulación básica en lo referente a la organización ejecutiva de los municipios del régimen común, permite que un municipio pequeño o mediano cuente con más libertad para establecer una organización municipal propia y diferenciada al amparo de su potestad de autoorganización; esto es, tienen más libertad, a la hora de decidir sobre su organización interna dado que la legislación básica no establece su modelo organizativo. En definitiva, las normas encargadas de conferir a los titulares de un determinado órgano directivo, la condición de directivo público han sido la norma básica de régimen local estatal o la normativa autonómica, por un lado y, las normas de autoorganización administrativa de cada entidad local, a través de sus Reglamentos orgánicos y de funcionamiento, por otro.

La reglamentación local tiene una importante limitación, el reglamento local no puede regular lo que esté materialmente reservado a la ley o previamente haya sido regulado en una norma con rango de ley. Sin embargo, tenemos que tener en cuenta, que la dirección pública profesional local forma parte consustancial de las potestades de autoorganización local y esta potestad se desarrolla necesariamente a través del Reglamento Orgánico de la Corporación. En definitiva, entendemos que tanto el plano de la organización como el de la dirección pública están superpuestos entre sí.

En la Administración local, la LRBRL es la encargada de especificar qué puestos de naturaleza directiva se encuadrarán dentro del personal directivo. Entendemos por tanto, que serán las normas autonómicas de desarrollo las que podrán introducir órganos directivos también en estos municipios dentro de sus respectivos territorios y, además, los reglamentos de organización y funcionamiento municipal pueden definir la estructura organizativa propia en cada corporación local. En fin, las normas de organización de cada Ayuntamiento serán las que concreten los puestos cuyos titulares han de tener la consideración de directivos, además a través de sus Relaciones de puestos de trabajos, pueden establecer las funciones del puesto y los requisitos de acceso.

\section{A MODO DE CONCLUSIÓN.}

Los resultados de nuestro análisis nos permiten extraer algunas conclusiones. EI marco normativo básico local institucionaliza los órganos directivos $y$, por lo tanto, la dirección pública profesional en los municipios de gran población y mantiene la organización especial en los municipios de régimen especial -Barcelona y Madrid-; sin embargo, olvida a la organización directiva en la mayoría de municipios españoles, para los que no se prevé una organización ejecutiva ni órganos directivos en sus estructuras organizativas.

Aunque parezca incomprensible, para los municipios de régimen común la normativa básica no prevé órganos directivos en sus estructuras básicas organizativas, a pesar de ello, introduce máximos órganos de dirección para su Administración dependiente: Organismos autónomos, Entidades públicas empresariales y empresas públicas locales; aunque sin contar con carácter de órgano directivo.

De esta forma, para la mayoría de los municipios españoles la normativa básica atribuye al Alcalde las facultades ejecutivas más importantes y, lo que es más significativo, el ejercicio de las principales competencias y funciones directivas en el seno de la 
organización municipal. Competencias ejecutivas que sólo puede delegar en algún otro Concejal, y no en un empleado municipal.

En los municipios de régimen común, la falta de institucionalización directiva, hace que desde un punto de vista material, podamos reconocer por una parte, una dirección política, representada por los electos locales, con importantes funciones administrativas y ejecutivas; y, por otra, una dirección puramente burocrática, siempre que el Reglamento orgánico municipal o la relación de puestos de trabajo, lo califique, como de directivo y le atribuya el ejercicio de funciones de gestión o ejecución de carácter superior; aunque sin contar con el carácter de órgano directivo. Así pues, excluyendo al personal eventual, pueden realizar funciones directivas en estos municipios: el directivo-funcionario de carrera propio de la Corporación; el directivo-funcionario habilitado nacional, que junto a sus funciones reservadas, desarrolle funciones directivas; $y$, por último, el directivopersonal laboral, procedente de la propia corporación o del sector privado, y sujeto al contrato laboral especial de alta dirección.

En fin, a falta de reconocimiento de órganos directivos por la legislación básica de régimen local, nada impide que la legislación autonómica pueda diseñar una organización directiva también para estos municipios. Posibilidad ésta perfectamente acorde con nuestro desarrollo constitucional siempre y cuando los Estatutos de Autonomía respectivos hayan asumido como propias las competencias en materia de régimen local.

\section{BIBLIOGRAFIA}

Font i Llovet, T. 2011. Uniformidad y diferenciación en las instituciones autonómicas y locales en España: Aquiles y la tortuga, en LÓPEZ MENUDO, F. (coord.), Derechos y garantías del ciudadano: estudios en homenaje al profesor Alfonso Pérez Moreno, lustel, Madrid.

García Roca, J. 2001. El concepto actual de autonomía local según el bloque de la constitucionalidad, en LÓPEZ GUERRA, L. (Coord.), Estudios de Derecho Constitucional, Homenaje al Profesor Dr. D. Joaquín García Morillo, Tirant lo Blanch, Valencia.

Jiménez Asensio, R. 1994. "La función directiva en el sector público español: tipología de regímenes jurídicos de los directivos públicos", en Documentación Administrativa, núm. 241-242, enero-agosto. 1995, págs. 273 a 405.

Jiménez Asensio, R. 1998. "Políticos, directivos y empleados públicos: problemática de la dirección pública en la administración local”, en Castillo Blanco, F. A (coord.), Situación actual y tendencias de la función pública española, Comares, Granada.

Jiménez Asensio, R. 2013. "La reforma local: primer análisis de la Ley de Racionalización y Sostenibilidad de la Administración Local. Contexto, elementos estructurales y algunas pautas interpretativas para la aplicación de un marco normativo complejo", en Anuario aragonés del gobierno local, núm. 5, págs. 300 y ss.

Maeso Seco, L. F. 2011. El personal directivo público en España, La Ley, Madrid. 
Nieto, A. 1984. "Los estudios sobre la Administración Pública: la necesidad de construir una disciplina que no sea la base formativa de una clase directiva profesionalizada", en Documentación Administrativa, núm. 200, enero-marzo, 1984, págs.7 a 42.

OCDE. 2008. Public employment and Management Working Party, Public Governance and Territorial Development Directorate, Public Governance Committee, GOV/PGC/PEM (2008) 2, unclassified, 31-jan-2008.

Ortega Álvarez, L. 2000. Diferenciación frente a uniformismo en la organización territorial local, en Anuario del Gobierno Local 1999/2000, Marcial Pons-Diputación de Barcelona-Institut de Dret Públic, Barcelona, págs. 77-94.

Palomar Olmeda, A. 2005. Empleo público local, Bosch, Barcelona.

Pérez García, M. L. 2015. "la aplicación diferenciada o asimétrica de la ley de Racionalización y sostenibilidad de la Administración local en las distintas comunidades y ciudades autónomas ( $y$ en dos municipios: Madrid y Barcelona), en Gabilex, número extraordinario Jornadas de Letrados de las CCAA 15, 16 y 17 de abril de 2015, pág. 51-70.

Santamaría Pastor, J. A. 2004. Principios de Derecho Administrativo General, Vol. I., lustel, Madrid.

Velasco Caballero, F. 2009. Derecho local. Sistema de fuentes, Madrid, Marcial Pons. En especial los capítulos IV y V. Más reciente, véase Velasco Caballero, F. 2014. "Títulos competenciales y garantía constitucional de autonomía local en la Ley de Racionalización y Sostenibilidad de la Administración Local”, en Santamaría Pastor, J. A. (coord.), La reforma del 2013 del régimen local español, Fundación Democracia y Gobierno Local, Madrid, págs. 75-136.

Velasco Caballero, F. 2014. La ley de racionalización y sostenibilidad de la administración local en el sistema de derecho local, en DOMINGO ZABALLOS, M. J. (coord.), Reforma del Régimen Local. La Ley de Racionalización y Sostenibilidad de la Administración Local: Veintitrés estudios, Aranzadi, Cizur Menor.

Villoria Mendieta, M. 2000. Unidad didáctica 15 "La función directiva en las Administraciones Públicas", en Villoria Mendienta, M y del Pino Matute, E. (Dir). Manual de Gestión de Recursos Humanos en las Administraciones Públicas, 2 ed., Edit. Tecnos, Madrid. 